\title{
Russell Meyers (1905-1999): pioneer of functional and ultrasonic neurosurgery
}

\author{
Taylor J. Abel, MD, Timothy Walch, PhD, and Matthew A. Howard III, MD \\ Department of Neurosurgery, University of lowa, lowa City, lowa
}

\begin{abstract}
Advances in functional neurosurgery, including neuromodulation and more recently ultrasonic ablation of basal ganglia structures, have improved the quality of life for patients with debilitating movement disorders. What is little known, however, is that both of these neurosurgical advances, which remain on the cutting edge, have their origin in the pioneering work of Russell Meyers, whose contributions are documented in this paper. Meyers' published work and professional correspondence are reviewed, in addition to documents held by the Department of Neurosurgery at the University of lowa. Meyers was born in Brooklyn, New York, and received his neurosurgical training at hospitals in New York City under Jefferson Browder. In 1939, a chance encounter with a young woman with damaged bilateral ventral striata convinced Meyers that the caudate could be resected to treat Parkinsonism without disrupting consciousness. Shortly thereafter, he performed the first caudate resection for postencephalitic Parkinsonism. In 1946, Meyers became the first chairman of neurosurgery at the State University of lowa (now the University of lowa), which led to the recruitment of 8 faculty members and the training of 18 residents during his tenure (1946-1963). Through collaboration with the Fry brothers at the University of Illinois, Meyers performed the first stereotactic ultrasonic ablations of deep brain structures to treat tremor, choreoathetosis, dystonia, intractable pain, and hypothalamic hamartoma. Meyers left academic neurosurgery in 1963 for reasons that are unclear, but he continued clinical neurosurgery work for several more years. Despite his early departure from academic medicine, Meyers' contributions to functional neurosurgery provided a lasting legacy that has improved the lives of many patients with movement disorders.

http://thejns.org/doi/abs/10.3171/2015.9.JNS142811
\end{abstract}

KEY WORDS history of neurosurgery; functional neurosurgery; stereotactic neurosurgery; basal ganglia; Parkinson disease

$\mathrm{T}$ HE application of neurosurgical techniques to alleviate functional conditions such as Parkinson disease, essential tremor, and other movement disorders has expanded substantially in recent years. Two of the most striking examples of this trend are the widespread availability of deep brain stimulation of basal ganglia structures to treat Parkinson disease and essential tremor, ${ }^{18}$ and more recently the application of MR-guided focused ultrasound to create lesions in the pallidum to treat essential tremor.,

It is commonly accepted that these two advances are now and will continue to be key procedures in the future of functional neurosurgery. What is little remembered, however, is that both procedures (i.e., extrapyramidal intervention for movement disorders and focused ultrasonic lesions of subcortical brain structures) have their origins in the pioneering work of one American neurosurgeon: Russell Meyers (Fig. 1).

In 1946, Russell Meyers became the founder and first chairman of the Division of Neurosurgery at the State University of Iowa (SUI). He subsequently made numerous contributions to the field of functional neurosurgery, but citations of his contributions are limited in the neurosurgical literature.

One of the few sources available on Meyers' life is an interview with Meyers by historian and writer Roy Selby. ${ }^{19}$ Although valuable, this interview does not encompass the breadth of Meyers' work and contribution to the development of neurosurgery at the University of Iowa and around the world. It is fortunate, therefore, that Meyers' professional correspondence from his 17 years at Iowa sheds light on his role in the development of functional neurosurgery. In this paper we review Meyers' writings and correspondence from those years to describe his life and work, to give him credit for his vital contributions to the development of functional neurosurgery.

\section{Background and Neurosurgical Training}

Meyers was born in 1905 in Brooklyn, New York, the son of an architectural designer. Even though his father had 


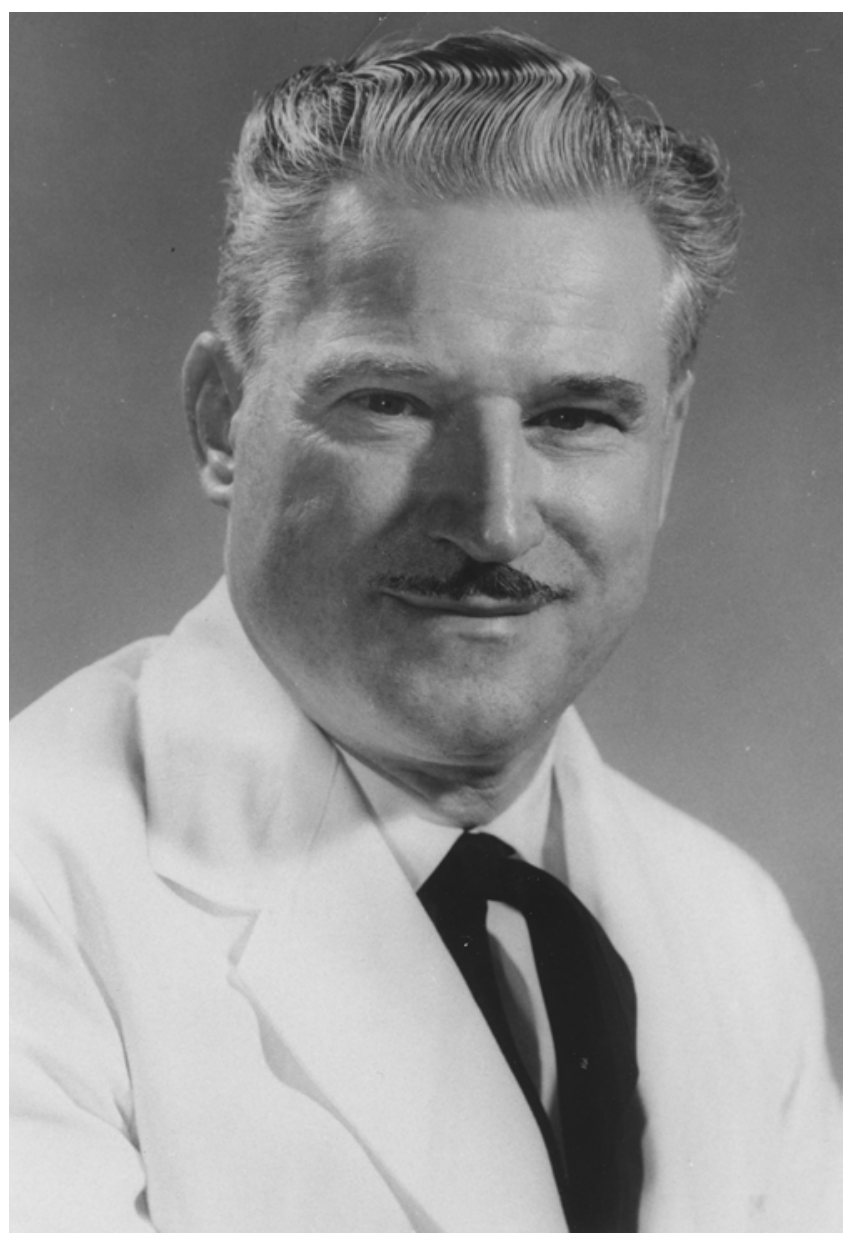

FIG. 1. Portrait of Russell Meyers during his time as chairman of the Division of Neurosurgery at the SUI. Used with permission of the Department of Neurosurgery Archives, University of lowa.

no specific career ambitions for young Russell, he did encourage his son's artistic talents, and that encouragement may have influenced his later neurosurgical ambitions. ${ }^{19}$ Meyers attended Brown University on an athletic scholarship to compete in track and field and graduated with an A.B. degree in 1927. Beginning in 1926, he financed his education by teaching experimental and physiological psychology at Brown and later at New York University. It was through his work as a laboratory assistant in biology courses that Meyers developed an early interest in physiology and psychology and completed an Sc.M. degree at Brown in 1929. His thesis was titled "A study of muscular tremors and their relation to emotional states in athletes under stress of competition."

After graduation from Brown, Meyers pursued a medical degree at Cornell University Medical College in New York City. As a medical student during the Great Depression, Meyers lived in a \$9-a-month apartment in Greenwich Village, a famously bohemian neighborhood on the lower west side of Manhattan. He financed his medical school education by teaching introductory psychology and physiological psychology courses to undergraduate students in the evening. In the summer months he taught day and night courses in abnormal and experimental psychology.
Apparently Meyers was able to handle both his teaching load and his medical school classes without any difficulty. In fact, Meyers was awarded the William Mecklenburg Polk Prize for highest honors in his class. During his junior year in medical school, he took Foster Kennedy's neurology course, in which he was awarded the Foster Kennedy Prize in Neurology. ${ }^{19}$ This achievement led to Meyers accepting a position on Foster Kennedy's neurology service at Bellevue Hospital several years later. He obtained his M.D. from Cornell University in 1932.

Although Meyers began his postgraduate training as a surgical intern at The Brooklyn Hospital, he was dismissed after only a few months for, in Meyers' words, "amusing reasons, but all of them professional."'19 Although his time at The Brooklyn Hospital was brief, Meyers did have the good fortune of working with Jefferson Browder, who had previously trained with Harvey Cushing. Meyers must have made quite an impression on Browder. When Browder learned of Meyers' dismissal from The Brooklyn Hospital, he offered him the first neurosurgery residency position at Kings County Hospital, also in Brooklyn.

After a year at Kings County Hospital, Meyers moved to Bellevue Hospital in New York City, where he studied neurology and neurosurgery for a second time under the auspices of Foster Kennedy and finished in 1935. He then completed a fellowship at the Lahey Clinic in Boston from 1935 to 1936, after which he returned to Brooklyn to complete additional training in the form of a formal preceptorship with Browder.

Interestingly, it was during his time in the research laboratory in the 1930s that Meyers first became interested in surgery for epilepsy. His interest eventually led to a Rockefeller Fellowship to go to Breslau to train with Otfrid Foerster; unfortunately, world affairs interceded. Foerster's wife was Jewish, and the family came under significant harassment from the German government. This injustice led Foerster to slow his practice considerably, thereby preventing Meyers from starting his Rockefeller Fellowship in Germany.

Over the next several years, Meyers worked at various hospitals in Brooklyn including Methodist Hospital, Holy Family Hospital, The Brooklyn Hospital, and The Samaritan Hospital. His next position, except for military service, would be at the SUI in Iowa City. It would be his one and only formal appointment in academic medicine.

\section{Initial Practice and Development of Extrapyramidal Surgery for Movement Disorders}

On March 7, 1939, while an assistant neurosurgeon at Kings County Hospital, Meyers performed an operation that would forever change the neurosurgical management of movement disorders, specifically Parkinson disease.., 19 At the time, neurosurgical treatments for Parkinson disease and other movement disorders were ablative. The history and evolution of neuroablative operations for movement disorders are reviewed in detail elsewhere., ${ }^{1,6,20}$ Important contributions had been made previously by Tracy Putnam, who made lesions of the spinal pyramidal tract, ${ }^{17}$ and others including Paul Bucy, who made lesions 
in the motor cortex, ${ }^{2}$ both for the treatment of severe tremor. Understandably, because these techniques lesioned the pyramidal tract itself, they did not specifically alleviate the symptoms of Parkinson disease because they were associated with motor deficit.

Despite the substantial risk of hemiparesis related to these operations, many patients with severe movement disorders went ahead with these operations, because any chance of improvement was better than stasis. Adding to the case for surgery was the fact that there were no other effective treatments available for patients with severe movement disorders.

Meyers thought he might be able to improve functional outcomes for patients with Parkinson disease by operating selectively on the extrapyramidal system in the basal ganglia. Specifically, he planned to selectively lesion either the caudate nucleus or the pallidofugal fibers of ansa lenticularis. He approached his then mentor, Browder, about the prospect of selectively lesioning the caudate nucleus. Browder, however, cautioned against the procedure because Walter Dandy had promulgated the idea that the ventral striatum was necessary for consciousness. ${ }^{2}$

But a chance encounter with an emergency room patient changed the course of Meyers' career forever. ${ }^{10,19}$ Meyers was on call at Kings County Hospital when a young woman, the daughter of a Columbia University professor, arrived in the emergency room after accidentally walking into a spinning propeller at an airfield. Through an open skull fracture, Meyers could see that this patient had obvious and severe trauma to the bilateral frontal lobes including the bilateral ventral striata. Despite complete damage of the bilateral ventral striata, the patient was conscious and followed commands. Given that this patient with bilateral ventral striata lesions was awake, Meyers concluded that the ventral striata must not be necessary for consciousness, as had been posited by Dandy. Meyers summoned Browder to the emergency room where the two doctors examined the patient together and arrived at the same conclusion regarding the necessity of the ventral striata for consciousness.

Shortly thereafter Meyers evaluated a 26-year-old woman with history of encephalitis who was severely disabled by postencephalitic left hemiparkinsonism. ${ }^{10}$ This woman was so disabled by her condition that her husband had abandoned her and she was unable to maintain any type of employment. In fact, her disability was so acute that she had contemplated suicide and had requested amputation of her left upper extremity. On March 7, 1939, Meyers performed an innovative basal ganglia operation to alleviate this woman's tremor. While the patient was under local anesthesia, Meyers performed a right transcortical transventricular resection of the anterior twothirds of the caudate nucleus (Fig. 2). He approached the ventricle through the frontal lobe using cortical stimulation mapping to ensure he was not lesioning the primary motor cortex. With the patient awake, Meyers recalled the tremor disappearing immediately after removal of the anterior caudate. Postoperatively, the patient's tremor was greatly reduced..$^{10}$

By November 4, 1940, Meyers had performed his sixth basal ganglia operation, which was his first attempt to treat tremor by selectively lesioning the ansa lenticularis.
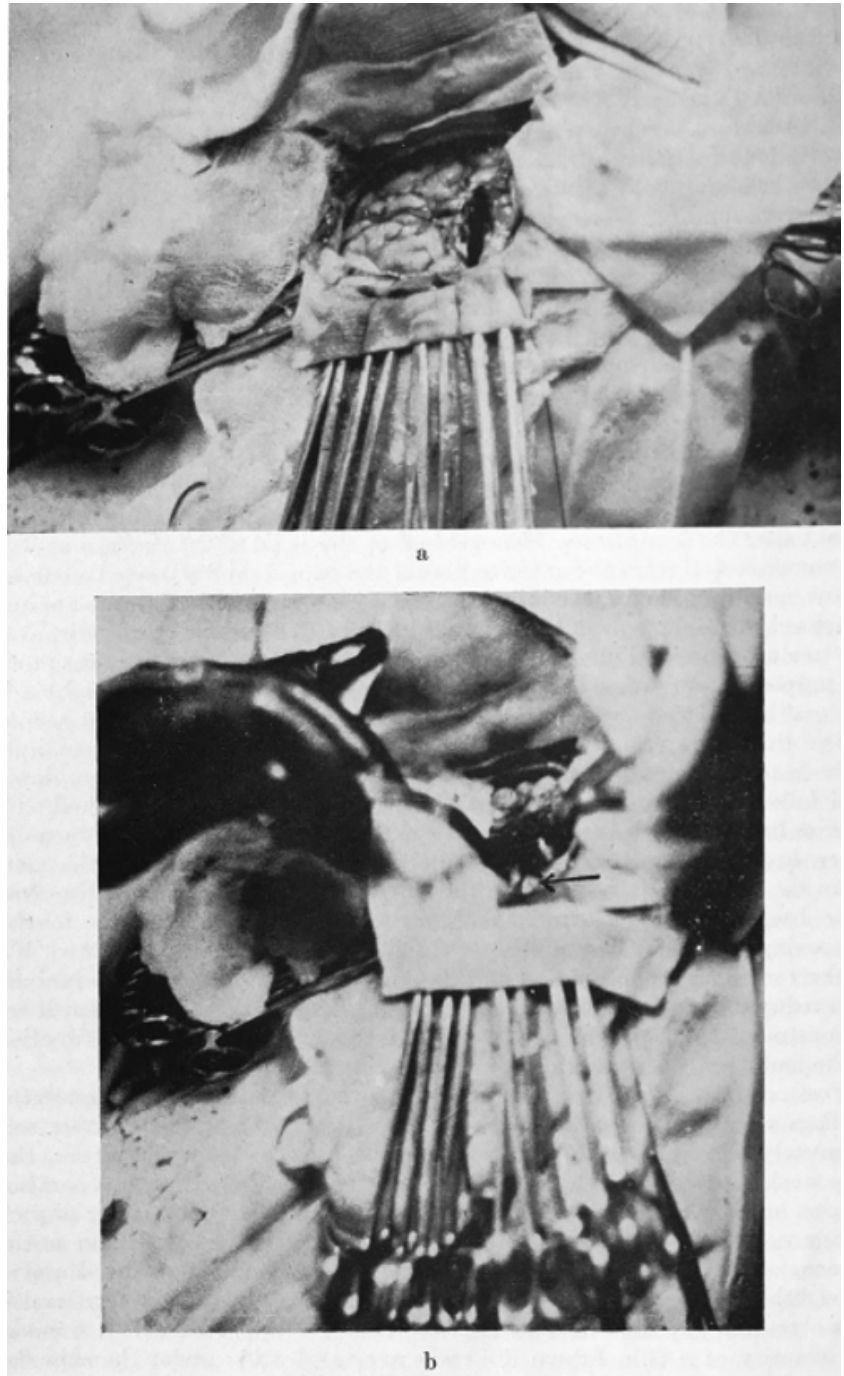

FIG. 2. Photographs of one of Meyers' first caudate resection operations for tremor. ${ }^{9}$ The upper photograph (a) depicts Meyers' approach and exposure of the frontal lobe with corticectomy to expose the lateral ventricle for access to the caudate nucleus. The lower photograph (b) demonstrates retraction of the frontal lobe to expose the caudate nucleus (arrow). Reproduced with permission from Meyers R: Res Publ Ass Nerv Ment Dis 21:602-665, 1942.

The patient died days later due to postoperative pneumonia, but Meyers saw improvement in tremor and used this operation for his future tremor patients. By 1942, Meyers had performed a variety of similar operations on the basal ganglia for other patients with tremor. ${ }^{9}$

The early results of this technique were so promising that Tracy Putnam addended one of his early case series in which he had produced lesions of the lateral pyramidal tract to include a patient he had treated with an operation similar to that performed by Meyers. ${ }^{9}$ Within a decade of his first operation for hemi-Parkinsonism, Meyers had performed a total of 58 basal ganglia operations with reported improvement in $69 \%$ of patients (letter from R. T. Tidrick to H. E. Ungerleider, January 12, 1959, University of Iowa Department of Neurosurgery Archives).

After his preliminary experience with the use of extrapyramidal lesions to treat movement disorders, Meyers 
realized that small lesions of specific subcortical structures (e.g., the ansa lenticularis) could have a significant impact on the symptoms of movement disorders. This realization led to Meyers' interest in the use of stereotactic instrumentation to guide focused lesioning of subcortical brain structures. Through the use of stereotaxy, Meyers reasoned that he could access the basal ganglia with less damage to the overlying cerebral cortex.

\section{World War II and Recruitment to lowa}

Meyers' work in New York ended when he entered the Army Medical Corps on November 5, 1942, at the rank of captain and was deployed in Europe as chief of the neurosurgical service in the 79th General Hospital in Belfast, Ireland. In Belfast, Meyers cared for patients who had suffered injuries from German bombing missions. After serving in Belfast, Meyers transferred to the 91st General Hospital in Oxford, England, where he was first an assistant to neurosurgeon Major Ted Scarff and eventually served as chief of neurosurgery from 1944 to 1945 . During his time overseas, Meyers also served as chief of service of the 178th General Hospital in Rheims, France (1945). He completed his military service as chief of the Neurosurgical Center at Mayo General Hospital in Galesburg, Illinois (1945-1946) and was honorably discharged from military service on June 27, 1946.

It is interesting to note that the 91st General Hospital in Oxford was started by a medical team from the SUI, and it was at Oxford that Meyers first encountered some of his future colleagues. ${ }^{19}$ In fact, it was during his time at Oxford that Meyers made connections that lead to his recruitment to head the new Division of Neurosurgery at Iowa (Fig. 1).

What is not known, however, is exactly why Meyers chose Iowa or what factors directly led to his recruitment. We can discern from internal SUI documents and correspondence that having a surgeon specialized in neurosurgery was a great priority for the department. In fact, the position was attractive enough that there was competition for it. In June of 1945, George Perret, who would eventually became chairman of the Division of Neurosurgery at Iowa, began a chain of correspondence with the dean and the then head of general surgery at SUI to inform them of his interest in the position (letter from G. Perret to E. M. MacEwen, June 18, 1945, University of Iowa Department of Neurosurgery Archives). Interestingly, this suggests that George Perret and Russell Meyers were in direct competition for the SUI neurosurgery position.

On December 13, 1945, Perret received a formal letter that rejected his application for the neurosurgery position (letter from F. R. Peterson to G. Perret, December 13, 1945, University of Iowa Department of Neurosurgery Archives). This is the only extant documentary evidence that suggests that Meyers had been selected for the position.

Additionally, evidence from the same records indicates that there was a strong drive to recruit a new neurosurgeon after the departure of Olan Hyndman for private practice in Colorado in 1939. Even though Hyndman was the second highest paid surgeon at SUI, additional funds were allocated for a neurosurgery position after Hyndman's departure.
It is also quite possible that Meyers knew of Iowa from Anatole Kolodny, SUI's first neurosurgeron, who had worked at SUI from 1924 to 1930 and had had substantial academic success. Kolodny later moved into private practice in New York City and would have worked at hospitals in Brooklyn at the same time that Meyers was a resident in Brooklyn. ${ }^{4}$ Thus, it is possible that interaction between Meyers and Kolodny influenced Meyers' decision to come to Iowa.

\section{A New Division of Neurosurgery at the State University of lowa}

There is no question that Meyers' arrival at Iowa changed him and the practice of neurosurgery at the university. Prior to his appointment, there had been only sporadic neurosurgery coverage at Iowa, with most neurosurgeons working only a few years (e.g., Anatole Kolodny [1924-1930] and Olan Hyndman [1933-1939]). The reason for such limited neurosurgical coverage is not known, but perhaps reflected the economic challenges of the time.

Although formal neurosurgery coverage was inconsistent until 1946, neurosurgery was performed at the SUI Hospital beginning in the 1920s by Anatole Kolodny (1924-1930), Earl Walker (1934-1935), and Olan Hyndman (1933-1939). During Olan Hyndman's temporary departure from Iowa (1933-1935) to complete a Rockefeller Fellowship with Wilder Penfield, Tracy Putnam, and Walter Dandy, the university's neurosurgical service was covered by Earl Walker who had just finished residency training at the University of Chicago. During his time at Iowa, Walker wrote a manuscript internally published by the SUI Department of General Surgery in which he retrospectively reviewed patients who underwent surgical intervention for skull fracture as early as 1920 (A. E. Walker, "Skull Fractures," Department of General Surgery Bulletin, 1934-1935). Thus, despite only sporadic coverage by surgeons experienced in neurosurgery, there was a great need for a more permanent and specialized neurosurgeon at Iowa.

Meyers' arrival in Iowa in 1946 marked the beginning of a dramatic transformation in academic neurosurgical practice at Iowa. Indeed, his appointment reflected the university's commitment to establishing a substantive neurosurgical practice in the state. Perhaps the best example of this commitment was evident in the expansion of the faculty; by 1952, Meyers had recruited 3 new faculty members who remained at Iowa until his departure in 1963 (Table 1). Important faculty recruits included George Perret (hired in 1949), Miles Skultety (hired in 1952), and Herbert Locksley (hired in 1959). In addition, Olan Hyndman was recruited back to the SUI in 1952 to head the new neurosurgery practice at the Iowa City Veterans Administration Hospital and hold an adjunct academic appointment at the university. Each faculty member became involved in academic endeavors, which set the tradition of academic neurosurgery at Iowa that continues to the present day.

Perhaps Meyers' most important accomplishment as division head was establishment of the neurosurgery residency training program. Residents were a priority for Meyers, a commitment that was reflected in numerous letters 
TABLE 1. Faculty recruited to the SUI by Russell Meyers

\begin{tabular}{cc}
\hline \multicolumn{1}{c}{ Name } & Years at the SUI \\
\hline George E. Perret & $1949-1976$ \\
\hline Jess T. Schwidde & $1951-1952$ \\
\hline F. Miles Skultety & $1952-1966$ \\
\hline Olan R. Hyndman & $1952-1966^{*}$ \\
\hline Marco T. Eugenio & $1957-1958$ \\
\hline Charles W. Whitten & $1958-1959$ \\
\hline Herbert B. Locksley & $1959-1971$ \\
\hline Hiro Nishioka & $1963-1967$ \\
\hline
\end{tabular}

* Hyndman headed neurosurgery at the lowa City Veterans Administration Hospital and held an adjunct appointment at the SUI.

between Meyers and his residency graduates. His loyalty to these residents was also reflected in communications between Meyers and hospital administrators, in which he often advocated for his residents. In one of many examples of this concern, Meyers went so far as to request special subsidized housing from the university provost for a resident and his family (letter from R. Meyers to H. H. Davis, July 26, 1951, University of Iowa Department of Neurosurgery Archives). In terms of clinical education, Meyers organized the residency program and was involved in the training of 18 neurosurgical residents (Table 2).

While at Iowa, Meyers' interest in functional neurosurgery continued, and his practice expanded over time. In his published work, he described the electrical activity of the basal ganglia (e.g., the caudate nucleus) in patients suffering from Parkinsonism and hemibalismus. ${ }^{13,14,16}$ It is important to note that in the course of this work, in collaboration with Robert Hayne, ${ }^{7}$ Meyers developed a novel new human stereotactic instrument. Meyers performed midbrain cruciotomies for patients with choreoathetotic cerebral palsy and took great interest in these patients. His concern and his accomplishments eventually led to Meyers' selection in 1961 as the president of the American Academy of Cerebral Palsy.

Psychosurgery was another facet of Meyers' neurosurgical practice. He performed both lobotomies and transorbital leukotomies at local mental hospitals not affiliated with the university hospital. Apparently he preferred the transorbital approach, and this belief is evident in a letter he wrote to Donald Sweeney:

As far as I can see, mortality, morbidity, and accessibility to the large number of patients that may profit from lobotomy is made possible by a transorbital approach...In any event, I am of the opinion that a good deal of the objection that has been raised to transorbital leukotomy by our colleagues has been raised on an emotional and esthetic basis, rather than on a sound empirical basis.

In the same letter, he noted having performed 13 transorbital leukotomies in as short as 55 minutes with neurosurgical resident Jess Schwidde (letter from R. Meyers to D. Sweeney, December 2, 1950, University of Iowa Department of Neurosurgery Archives).

Meyers was also interested in epilepsy surgery and by 1954 had operated on more than 90 patients believed to have focal epilepsy. ${ }^{11,15}$ Meyers used visual inspection,
TABLE 2. Residents trained by Russell Meyers at the SUI

\begin{tabular}{lc}
\hline Neurosurgical Resident & Years at the SUI \\
\hline Donald B. Sweeney & $1947-1949$ \\
\hline Jess T. Schwidde & $1948-1951$ \\
\hline John R. Williams & $1949-$ \\
\hline Gordon L. Smiley & $1950-1951$ \\
\hline Robert L. Imler & $1951-1953$ \\
\hline Spiridon G. Michalitsianos & $1952-1954$ \\
\hline Jesse H. Woolfolk & $1953-1954$ \\
\hline Gerald R. Nowlis & $1954-1956$ \\
\hline Robert C. Hardy & $1954-1955$ \\
\hline Arthur B. Eisenbury & $1955-1957$ \\
\hline Francis S. Walker & $1956-1959$ \\
\hline Donald F. Schultz & $1956-1960$ \\
\hline James W. Dyll & $1958-1962$ \\
\hline Robert E. Edgar & $1959-1961$ \\
\hline Edward H. James & $1959-1963$ \\
\hline Alan F. Wentworth & $1960-1964$ \\
\hline Daniel L. McKinney & $1960-1964$ \\
\hline Zeki A. Uygur & $1962-1965$ \\
\hline
\end{tabular}

palpation, and cortical stimulation to elicit seizures, and intraoperative interictal electrocorticography as a means to identify the epileptic focus. Meyers wrote in $1954^{11}$ that he was generally disappointed in his results of $11 \%$ seizure freedom and $23 \%$ reduction in seizure frequency. Interestingly, the departmental interest in epilepsy surgery that Meyers started continues on today.

\section{The Fry Brothers and Ultrasonic Neurosurgery}

One of Meyers' other achievements resulted from his collaboration with William and Frank Fry at the University of Illinois to develop and use stereotactically focused ultrasound to perform selective brain ablations in humans (Fig. 3). In the early 1950s, the Fry brothers demonstrated the use of focused ultrasound to generate specific lesions in the cat brain. ${ }^{5}$ In an interuniversity collaboration between Meyers and the Fry brothers, stereotactic targeting of ultrasonic irradiation was applied to patients suffering from various movement disorders. A specialized operating room was built at the SUI Hospital to facilitate use of the ultrasound apparatus, which was too large to fit into a standard operative theater (Fig. 3). In this operating room, Meyers would perform a craniotomy and then perform ultrasonic irradiation of various targets with stereotactic guidance. In 1959, Meyers and the Fry brothers published their preliminary results of using focused ultrasound to lesion pallidofugal fibers for the treatment of tremor. ${ }^{12}$

Meyers and his colleagues went on to use intense focused ultrasound to selectively lesion deep brain targets in an attempt to treat Parkinsonism, choreoathetotic cerebral palsy, thalamic pain syndrome, phantom limb pain, malignant breast cancer (via pituitary interruption), and hypothalamic hamartoma. ${ }^{4}$ This was revolutionary in neurosurgery; for the first time, deep brain structures could be 


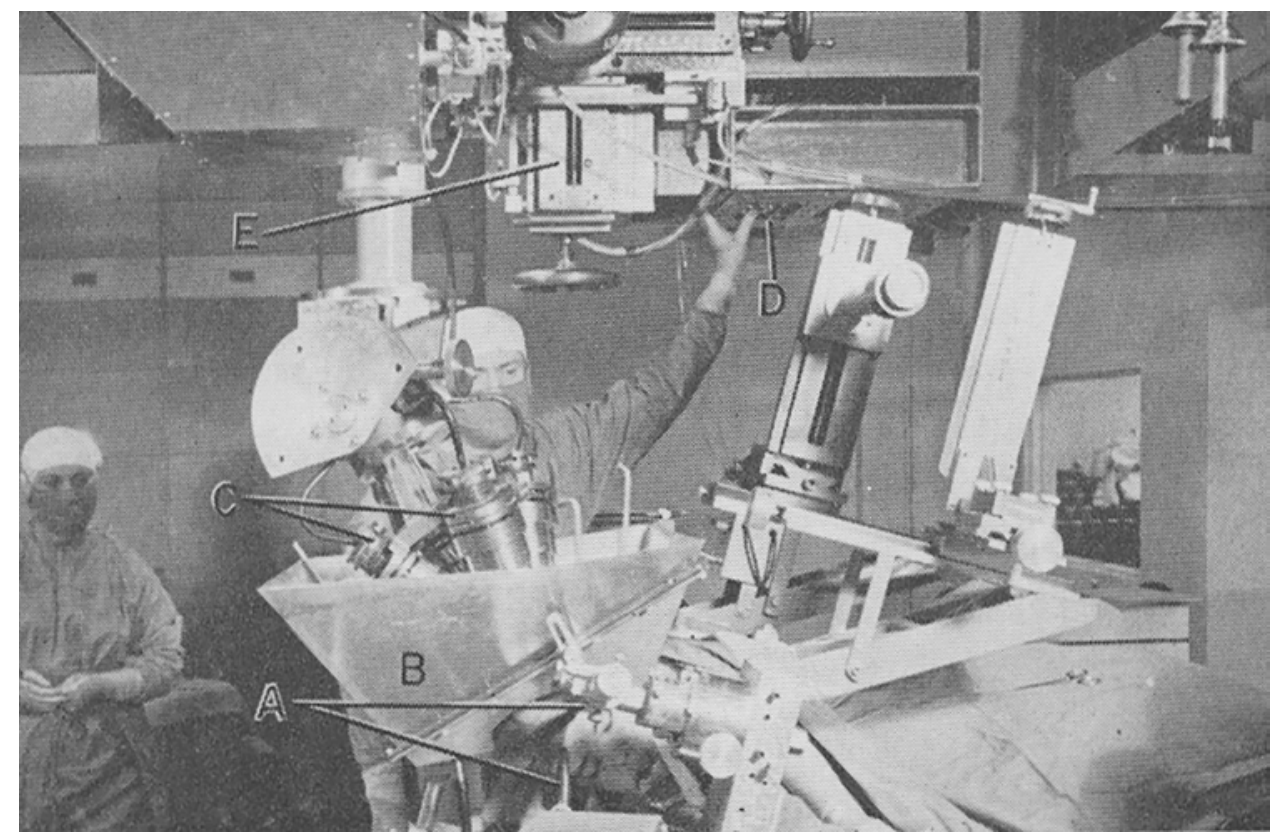

FIG. 3. Stereotactic ultrasonic neurosurgery apparatus in the operating room. Used with permission of the Department of Neurosurgery Archives, University of lowa.

lesioned by a neurosurgical approach through superficial brain structures without causing damage.

Because of this work, Robert Tidrick, head of the Department of General Surgery at the SUI, nominated Meyers for the Oscar B. Hunter Memorial Award in 1959 (letter from R. T. Tidrick to H. E. Ungerleider, January 12, 1959). Meyers published several papers with the Fry brothers, and the relatively short duration of their collaboration (1950s to 1960) was probably an unfortunate byproduct of Meyers' departure from Iowa City.

\section{Personal Life and Outside Interests}

Meyers was an interesting and engaging individual outside the medical community. Of particular note, he was known to spend his free time playing jazz piano at social gatherings at the Iowa Memorial Union (Fig. 4). In fact, during World War II, Meyers frequently entertained troops stationed at the 91st Hospital at Oxford by playing the "Boogie Woogie" on the piano and on at least 1 occasion played piano for the duke and duchess of Marlborough! Meyers also maintained an avid interest and personal involvement in track and field, an interest that continued at least until 1981, when he competed in masters division track and field competitions. In fact, Meyers won several world championships and set world records for his age group. ${ }^{19}$

Meyers also had a substantive interest in the general semantics movement and that led to his publication of numerous articles concerning general semantics and education in general. General semantics is a field concerned with the relationship between words and their referents that grew in popularity after World War II, perhaps in reaction to the perceived power of propaganda during the war. Meyers' interest in general semantics began in the mid-1930s when he happened upon an open copy of Alfred Korzybski's Science and Sanity in a Brooklyn medical library. While at Iowa, Meyers developed a personal friendship and pro- fessional partnership with other proponents of the general semantics movement including speech and hearing science pioneer Wendell Johnson and prominent astrophysicist James Van Allen. His interest in general semantics was so strong that between 1937 and 1963, he published more than 20 papers concerning general semantics or education in general.

\section{Departure From the SUI}

In 1963, for reasons that are not completely understood, Meyers left Iowa and never returned to academic neurosurgery. Letters between Meyers and university president Virgil Hancher suggest that the reasons for departure were not ideal, but completely unrelated to Meyers' professional activities (letter from R. Meyers to V. M. Hancher, May 31, 1963, University of Iowa Department of Neurosurgery Archives). Interestingly, evidence shows that Meyers' plans after leaving the SUI were uncertain. He applied for jobs at various private hospitals and at least 1 Veterans Administration medical center. There is also evidence that Meyers sought employment outside of neurosurgery when he applied for a position as a neuropsychiatrist at the Colorado State Hospital (letter from P. Binney to R. T. Tidrick, April 26, 1963, University of Iowa Department of Neurosurgery Archives). Ultimately, Meyers found employment with the Miners Memorial Hospital Association in Williamson, West Virginia. From 1963 until his retirement from neurosurgery in 1975, Meyers served as chief of staff of neurology and neurosurgery at the Appalachian Regional Hospital (a community hospital).

Although it is clear that Meyers' departure from Iowa in 1963 was unusual and less than ideal, there is substantial evidence that his departure was lamented across the university. Letters from Hancher, Tidrick, and Robert Hardin (dean of the school of medicine), all indicate regret for Meyers' departure. In fact, Meyers maintained per- 


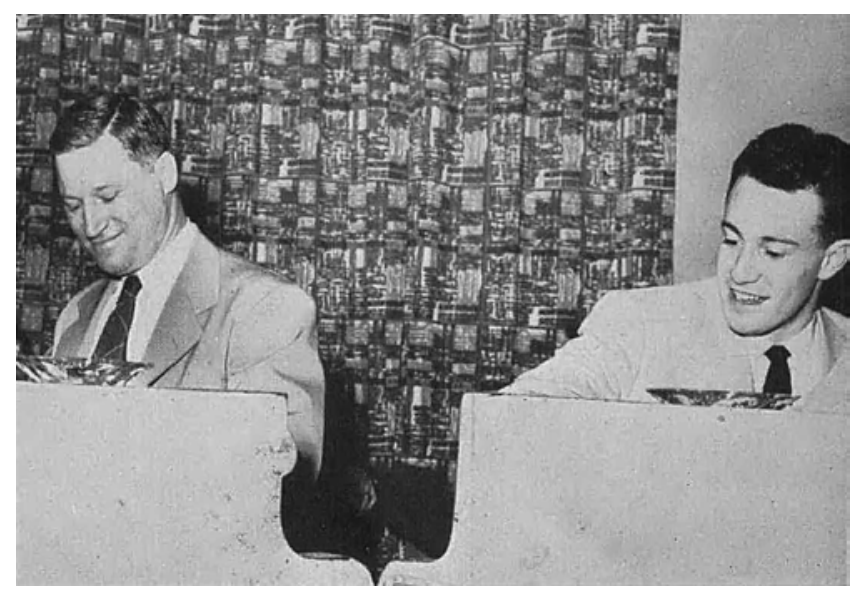

FIG. 4. Russell "Doc" Meyers (left) playing a duet at an lowa Memorial Union dance. From a 1950s Hawkeye yearbook, University of lowa Archives.

sonal ties with Tidrick for several years as demonstrated by numerous personal handwritten letters between the two men during Meyers' time in West Virginia. In 1966, when Olan Hyndman died suddenly from a massive myocardial infarction, Meyers sent Tidrick a eulogy describing Hyndman's underappreciated contributions to neurosurgery at the university. Despite his departure from Iowa, Meyers valued his continued communication with his Iowa colleagues.

Even though he never held another academic appointment after Iowa, Meyers' interest in general semantics persisted, and he presented the Alfred Korzybski Memorial Lecture in general semantics in 1985. He died in 1999 at the age of 95 .

Russell Meyers' life and work had a profound influence on the practice of functional neurosurgery as we know it today. Indeed, there is a direct connection between foundational conceptualization, creativity, and vision pioneered by Meyers in the 1950s and current practice in functional neurosurgery. If for that reason alone, the current practice of neurosurgery owes a debt of gratitude to Russell Meyers.

\section{Acknowledgments}

Dr. Abel is supported by a grant through the NIH (no. F32NS087664). This work was supported by the Ralph H. and Freda E. Ojemann Fund.

\section{References}

1. Benabid AL, Chabardes S, Torres N, Piallat B, Krack P, Fraix $\mathrm{V}$, et al: Functional neurosurgery for movement disorders: a historical perspective. Prog Brain Res 175:379-391, 2009

2. Bucy PC: Cortical extirpation in the treatment of involuntary movements. Am J Surg 75:257-263, 1948

3. Elias WJ, Huss D, Voss T, Loomba J, Khaled M, Zadicario E, et al: A pilot study of focused ultrasound thalamotomy for essential tremor. N Engl J Med 369:640-648, 2013

4. Elsberg CA: The development of neurological surgery in New York City during the past twenty-five years: With remarks on advances due to experiences in the First World War. Bull N Y Acad Med 18:654-664, 1942

5. Fry WJ, Mosberg WH Jr, Barnard JW, Fry FJ: Production of focal destructive lesions in the central nervous system with ultrasound. J Neurosurg 11:471-478, 1954
6. Gabriel EM, Nashold BS Jr: Evolution of neuroablative surgery for involuntary movement disorders: an historical review. Neurosurgery 42:575-591, 1998

7. Hayne R, Meyers R: An improved model of a human stereotaxic instrument. J Neurosurg 7:463-466, 1950

8. Lipsman N, Schwartz ML, Huang Y, Lee L, Sankar T, Chapman M, et al: MR-guided focused ultrasound thalamotomy for essential tremor: a proof-of-concept study. Lancet Neurol 12:462-468, 2013

9. Meyers R: The modification of alternating tremors, rigidity, and festination by surgery of the basal ganglia. Res Publ Ass Nerv Ment Dis 21:602-665, 1942

10. Meyers R: Surgical procedure for postencephalitic tremor with notes on the physiology of premotor fibers. Arch Neurol Psychiatry 44:455-459, 1940

11. Meyers R: The surgical treatment of focal epilepsy: an inquiry into current premises, their implementation and the criteria employed in reporting results. Epilepsia 3:9-36, 1954

12. Meyers R, Fry WJ, Fry FJ, Dreyer LL, Schultz DF, Noyes RF: Early experiences with ultrasonic irradiation of the pallidofugal and nigral complexes in hyperkinetic and hypertonic disorders. J Neurosurg 16:32-54, 1959

13. Meyers R, Hayne R: Electrical potentials of the corpus striatum and cortex in parkinsonism and hemiballismus. Trans Am Neurol Assoc 73 (73 Annual Meet):10-14, 1948

14. Meyers R, Hayne R, Knott J: Electrical activity of the neonstriatum, paleostriatum and neighbouring structures in parkinsonism and hemiballismus. J Neurol Neurosurg Psychiatry 12:111-123, 1949

15. Meyers R, Knott JR, Hayne RA, Sweeney DB: The surgery of epilepsy; limitations of the concept of the cortico-electrographic "spike" as an index of the epileptogenic focus. J Neurosurg 7:337-346, 1950

16. Meyers R, Sweeney DB, Schwidde JT: Hemiballismus: aetiology and surgical treatment. J Neurol Neurosurg Psychiatry 13:115-126, 1950

17. Putnam TJ: Relief from unilateral paralysis agitans by section of the pyramidal tract. Arch Neurol Psychiatry 40:1049-1050, 1938

18. Rodriguez-Oroz MC, Obeso JA, Lang AE, Houeto JL, Pollak $\mathrm{P}$, Rehncrona S, et al: Bilateral deep brain stimulation in Parkinson's disease: a multicentre study with 4 years follow-up. Brain 128:2240-2249, 2005

19. Selby RC, Meyers R: Russel Meyers, MD, interviewed by Roy C. Selby, MD. Leaders in Neuroscience: An Archives Video-Interview Series. Rolling Meadows, IL: American Association of Neurological Surgeons, 1989 (https://itunes. apple.com/us/itunes-u/leaders-in-neuroscience-archives/ id469533044? $\mathrm{mt}=10$ ) [Accessed November 4, 2015]

20. Speelman JD, Bosch DA: Resurgence of functional neurosurgery for Parkinson's disease: a historical perspective. Mov Disord 13:582-588, 1998

\section{Disclosures}

The authors report no conflict of interest concerning the materials or methods used in this study or the findings specified in this paper.

\section{Author Contributions}

Conception and design: Abel, Walch. Drafting the article: Abel, Walch. Critically revising the article: all authors. Reviewed submitted version of manuscript: all authors. Approved the final version of the manuscript on behalf of all authors: Abel

\section{Correspondence}

Taylor J. Abel, Department of Neurosurgery, University of Iowa, 200 Hawkins Dr., Iowa City, IA 52242. email: taylor-abel@ uiowa.edu. 